Article

\title{
Biopolymer-Inspired N-Doped Nanocarbon Using Carbonized Polydopamine: A High-Performance Electrocatalyst for Hydrogen-Evolution Reaction
}

\author{
Duong Nguyen Nguyen ${ }^{1}\left(\mathbb{D}\right.$, Uk Sim ${ }^{2, *(\mathbb{D})}$ and Jung Kyu Kim ${ }^{1, *(\mathbb{D})}$ \\ 1 School of Chemical Engineering, Sungkyunkwan University (SKKU), Suwon 16419, Korea; \\ nguyendun@gmail.com \\ 2 Department of Materials Science \& Engineering, Engineering Research Center and Optoelectronics \\ Convergence Research Center, College of Engineering and College of AI Convergence, \\ Chonnam National University, Gwangju 61186, Korea \\ * Correspondence: usim@jnu.ac.kr (U.S.); legkim@skku.edu (J.K.K.); Tel.: +82-62-530-1718 (U.S.); \\ +82-31-290-7254 (J.K.K.)
}

Received: 16 March 2020; Accepted: 12 April 2020; Published: 15 April 2020

\begin{abstract}
Hydrogen-evolution reaction (HER) is a promising technology for renewable energy conversion and storage. Electrochemical HER can provide a cost-effective method for the clean production of hydrogen. In this study, a biomimetic eco-friendly approach to fabricate nitrogen-doped carbon nanosheets, exhibiting a high HER performance, and using a carbonized polydopamine (C-PDA), is described. As a biopolymer, polydopamine (PDA) exhibits high biocompatibility and can be easily obtained by an environmentally benign green synthesis with dopamine. Inspired by the polymerization of dopamine, we have devised the facile synthesis of nitrogen-doped nanocarbons using a carbonized polydopamine for the HER in acidic media. The N-doped nanocarbons exhibit excellent performance for $\mathrm{H}_{2}$ generation. The required overpotential at $5 \mathrm{~mA} / \mathrm{cm}^{2}$ is $130 \mathrm{mV}$, and the Tafel slope is $45 \mathrm{mV} /$ decade. Experimental characterizations confirm that the excellent performance of the $\mathrm{N}$-doped nanocarbons can be attributed to the multisite nitrogen doping, while theoretical computations indicate the promotion effect of tertiary/aromatic nitrogen doping in enhancing the spin density of the doped samples and consequently in forming highly electroactive sites for HER applications.
\end{abstract}

Keywords: polydopamine; PDA; carbon nanosheet; nitrogen-doped carbon; electrocatalysts; hydrogen-evolution reaction

\section{Introduction}

Hydrogen-evolution reaction (HER) has generated significant interest as a promising technology for efficient renewable energy conversion [1-6]. Currently, the most efficient catalysts for HER, in addition to Pt, are earth-abundant metals, such as transition-metal sulfides [7-9], carbides [10-12], phosphides [13-15], and borides [16-18], which can replace noble metals.

In recent years, nonmetallic heteroatom-doped carbon materials have been intensively studied for energy-related electrocatalytic water-splitting processes such as the oxygen-reduction reaction (ORR) [19-21], oxygen-evolution reaction (OER) [22-24], and HER [25-27] because of their excellent electrical conductivity, high surface area, tunable molecular structures, and strong tolerance to various electrolytes. More importantly, it is noteworthy that carbon materials can be engineered to exhibit specific catalytic capabilities for specific electrocatalytic reactions by varying the doping types, sites, and levels [21-23,27-31]. Although some of these have recently been developed as HER electrocatalysts [32-34], the employment of carbon-based nanomaterials as high-performance 
candidates has not been reported to date. Clearly, the HER performance of carbon materials is not comparable to that of metal-based catalysts and does not presently conform to the benchmarks [31,35] established by metal-based catalysts. In addition, previously reported carbon-based electrocatalysts still exhibit several limitations during the synthesis process. For example, the synthesis of CVD-graphene-based catalysts is significantly expensive and requires multiple gas sources with particular pressure control and multiple transfer processes after the synthesis [34]. (Reduced) graphene oxide-based catalysts are a satisfactory alternative to CVD-graphene-based catalysts; however, their synthesis is time-consuming, toxic, and highly exothermal [36,37]. Furthermore, carbon sources exert a significant influence on the preparation process and the (electro)chemical properties of the resultant electrocatalyst. Among the potential candidates, polydopamine (PDA) has emerged as a new carbon precursor in recent years [28,38-41]. PDA is the self-polymerized product of dopamine, which can be synthesized under mild aqueous conditions simulating marine conditions. Due to the presence of catechol groups, the resultant PDA exhibits strong adhesion to bulk substrates or organic and inorganic materials. Therefore, the PDA does not only serve as the functional layer for many applications [42-44] but is also a promising carbon source for the preparation of carbon-based materials. So far, although the structure of the PDA is still under debate, carbonized PDA (C-PDA) has been utilized as nitrogen-doped graphite [40,42].

In this study, we demonstrate that through a variety of chemical doping processes-active sites for the HER-can be generated in the C-PDA. Further, these active sites can enhance and control catalytic activity. By the self-polymerization of dopamine through the dipping method, PDA can be produced universally on the substrate surface [45]. This self-polymerization is so mild that the simple immersion of a target substrate (e.g., $\mathrm{Cu}$ foil in this study) in an aqueous solution containing dopamine immediately results in the spontaneous deposition of a PDA film. Owing to the layer structure [40], the thickness of the film can be engineered to the nanometer scale using the immersion time [38]. The calcination of the PDA is then achieved in a tube furnace at elevated temperatures in a nitrogen atmosphere. Because of the complexity of the oxidative self-polymerization of dopamine, the chemical disorder model has been preferentially used in recent studies to describe PDA $[39,46,47]$. However, after calcination, the C-PDA has been proposed as nitrogen-rich carbon nanosheets $[40,48]$ using the semiconductor model. In addition, the C-PDA film can be easily transferred to arbitrary substrates (e.g., Si wafer) by employing polymethylmethacrylate (PMMA), thus presenting a significant benefit over CVD-graphene. In addition, the combination of experimental characterizations and density functional theory (DFT) calculations jointly confirm the origin of this activity enhancement. The results confirm that the different sites of nitrogen doping are critical in the formation of catalytically active sites and enhancements in charge transfer. Considering $\mathrm{N}$ is the most important dopant in carbon materials for electrocatalysis, this promising synthetic method is expected to establish a robust foundation for the further exploration and development of nanostructural PDA-based carbon materials for broader applications [28,49].

\section{Experimental}

\subsection{Materials}

All the commercially available reagents and solvents were purchased from Sigma-Aldrich (Seoul, Korea)), Acros Organics (Seoul, Korea), or TCI chemicals (Tokyo, Japan), and were used as received without any further purification. The target substrate was purchased from commercial sources.

\subsection{Synthetic Procedure}

The PDA was synthesized according to the methods reported in previous literature [38], with some modifications (Figure 1a). In this study, a commercial copper foil was used as the substrate for coating the thin PDA film. After ultrasonic cleansing in acetone, isopropanol, and deionized (DI) water, the substrate was immersed in $45 \mathrm{ml}$ of Tris buffer (tris (hydroxymethyl) aminomethane solution, 
$10 \mathrm{mM}$ ) containing $2 \mathrm{mg}$ of dopamine chloride. The $\mathrm{pH}$ value of the Tris buffer was adjusted to 8.5 using $\mathrm{HCl}$. The coating polymerization was conducted at $25{ }^{\circ} \mathrm{C}$ without mechanical stirring. After one hour, the substrates were removed from the solution, cleaned with DI water several times, and dried overnight at $70^{\circ} \mathrm{C}$ in an oven.

(a)
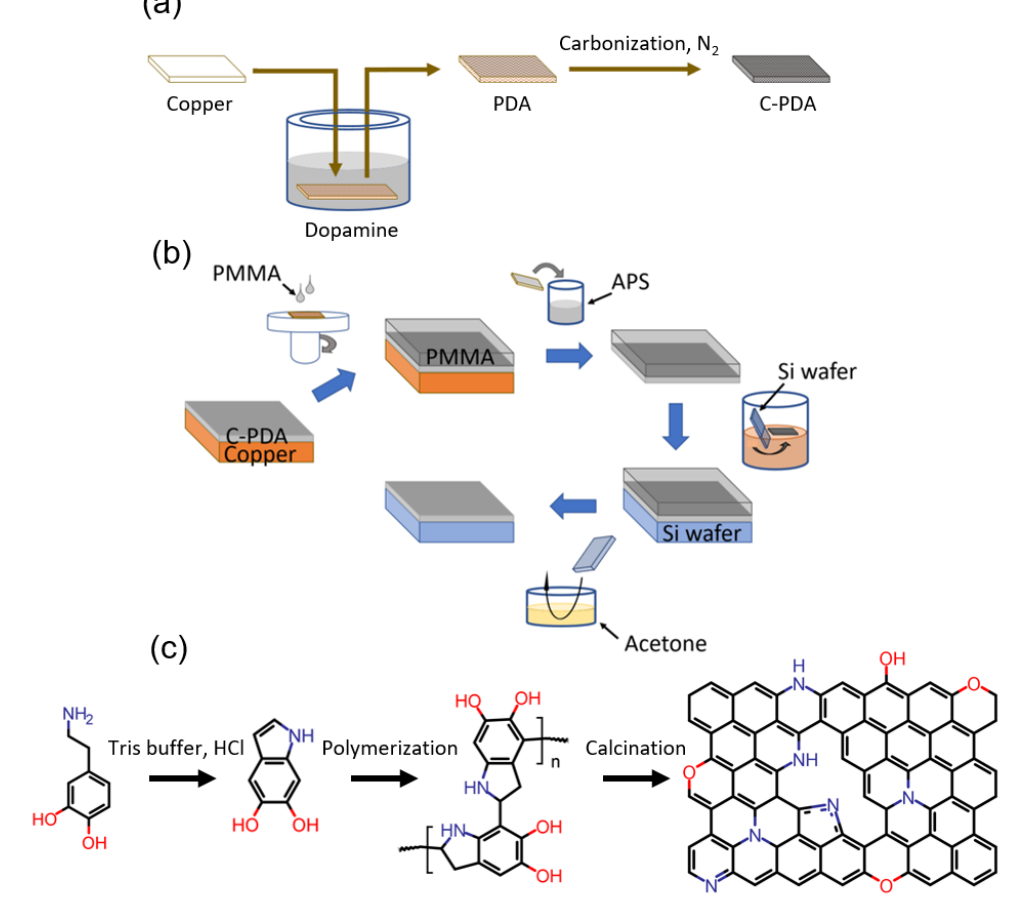

Figure 1. Fabrication of the carbonized polydopamine (C-PDA) for hydrogen generation. (a) Schematic of self-polymerization of dopamine on target substrate using the dipping method [38], (b) schematic showing the steps of the C-PDA film transfer onto Si wafer, (c) and the scheme of synthesis of N-doped carbon using dopamine as a precursor [50-52].

Substrates with PDA-coating were heat-treated under flowing nitrogen using a tube furnace. Using a typical heat treatment process, the system was heated at the heating rate of $10^{\circ} \mathrm{C} / \mathrm{min}$, fixed at the $800^{\circ} \mathrm{C}$ for an hour, and then cooled to room temperature naturally.

\subsection{Transfer of C-PDA onto Si Wafer}

The C-PDA was fabricated onto the Si surface by the following procedure (Figure 1b). First, the PMMA was spin-coated on the C-PDA/copper substrate as a supporting layer. Then, the copper substrate was removed by immersing the PMMA/C-PDA/copper substrate in a diluted ammonium persulfate solution (0.2 M). After washing with DI water, the PMMA/C-PDA was then deposited on the Si wafer. Finally, the PMMA was removed by acetone, with the C-PDA as the remainder on the Si substrate. This sample was stored in a vacuum oven for further atomic force microscopy (AFM) characterization.

\subsection{Material Characterization}

The thin C-PDA film samples were collected on copper-coated carbon grids and examined using transmission electron microscopy (TEM) images obtained by using a JEM-2100 microscope (JEOL, Tokyo, Japan). AFM images were acquired under ambient conditions with a SPA-300HV model (Seiko, Tokyo, Japan) operated in the tapping mode. The Raman spectra were collected on a Renishaw micro-Raman spectroscope (Renishaw, Seoul, Korea) with a $514.5 \mathrm{~nm}$ Ar laser as the excitation source. The X-ray photoelectron spectroscopy (XPS) analysis was conducted on an ESCALAB 250 photoelectron microprobe (Thermo Scientific, Seoul, Korea) with monochromated $\mathrm{Al} \mathrm{K} \alpha$ radiation (1486.6 eV). 


\subsection{Electrochemical Measurement}

Electrochemical measurements were achieved with a $\mathrm{CHI} 780$ electrochemical analyzer $(\mathrm{CH}$ Instruments, Inc. Austin, TX, USA) using a standard three-electrode cell. A platinum foil and an $\mathrm{Ag} / \mathrm{AgCl}(3 \mathrm{M} \mathrm{NaCl})$ were used as the counter and reference electrodes, respectively. The working electrode was the glassy carbon (GC) tip (diameter $5.0 \mathrm{~mm}$ ) of a rotating disk electrode (RDE). The RDE test was performed at $1000 \mathrm{rpm}$ with a scan rate of $5 \mathrm{mV} / \mathrm{s}$. For comparison, $\mathrm{Pt} / \mathrm{C}$ was mixed under ultrasonication with a NAFION solution ( $5 \mathrm{wt} . \%$, Alfa, Seoul, Korea) to form a well-dispersed catalyst "ink". Then, $10 \mu \mathrm{l}$ of the catalyst ink was drop-casted onto the polished GC tip. All the potentials were reported with respect to the reversible hydrogen electrode (RHE) in $\mathrm{H}_{2}$-saturated $1 \mathrm{M}$ perchloric acid at $25^{\circ} \mathrm{C}$.

\subsection{Theoretical Calculation}

The software packages ORCA 4.2.0 and Gaussian 09 were used for calculations [53]. The geometries of all initial models were optimized by the DFT method using the Perdew-Burke-Ernzerhof exchange-correlation functional. The Ahlrichs (def2-SVP) basis set was used for all atoms. The dispersion forces (the DFT-D3 method proposed by Grimme et al. [54]) were considered for dispersion correction. The resolution of identity (RI) approximation was used to boost the calculation; however, it should be noted that it produced an insignificant error. All calculations were achieved in a vacuum environment.

\section{Results and Discussion}

\subsection{Morphology}

The morphologies and structures of the as-prepared C-PDA were investigated by TEM and AFM. The AFM analyses (Figure 2a-c) confirm that the PDA forms a uniform coating on the Si substrate with a thickness of approximately $31 \mathrm{~nm}$. After carbonization, the thickness of the C-PDA decreases to approximately $12 \mathrm{~nm}$ (Figure $2 \mathrm{~d}-\mathrm{f}$ ). It is noteworthy that the white islands in the AFM image are consistent with the carbon aggregations on the sheet during the annealing process. Figure $2 \mathrm{~g}$ shows the TEM images of the C-PDA sheet, which was heated at $800^{\circ} \mathrm{C}$ for $1 \mathrm{~h}$ at the heating rate of $10^{\circ} \mathrm{C} / \mathrm{min}$. It is interesting to note that there are several dark domains distributed in the C-PDA sheet, which consists of folding of a graphite-like thin film. Because of the layered structure of graphitic carbon, we can expect that the nanosized sheet not only functions as a supporting layer with high conductivity but also creates homogeneous vacancies inside the sheet planes. In the previous reports, the C-PDA structure usually exhibits micropores after the calcination steps [42,43,55], which would be beneficial to electrocatalytic mass transfer and gas diffusion. Moreover, ultrathin C-PDA nanosheets enable shorter pathways for charge migration from the bulk material to the reaction sites located on its surfaces. Therefore, charge carriers can travel faster in the material and on their surfaces to reach the active sites, thus enhancing the electrocatalytic efficiency. Additionally, we carefully measured the layer distance of these thin films and found that it is approximately $0.34 \mathrm{~nm}$, which is the typical distance between graphite stacking layers (Figure 2h) [56]. 

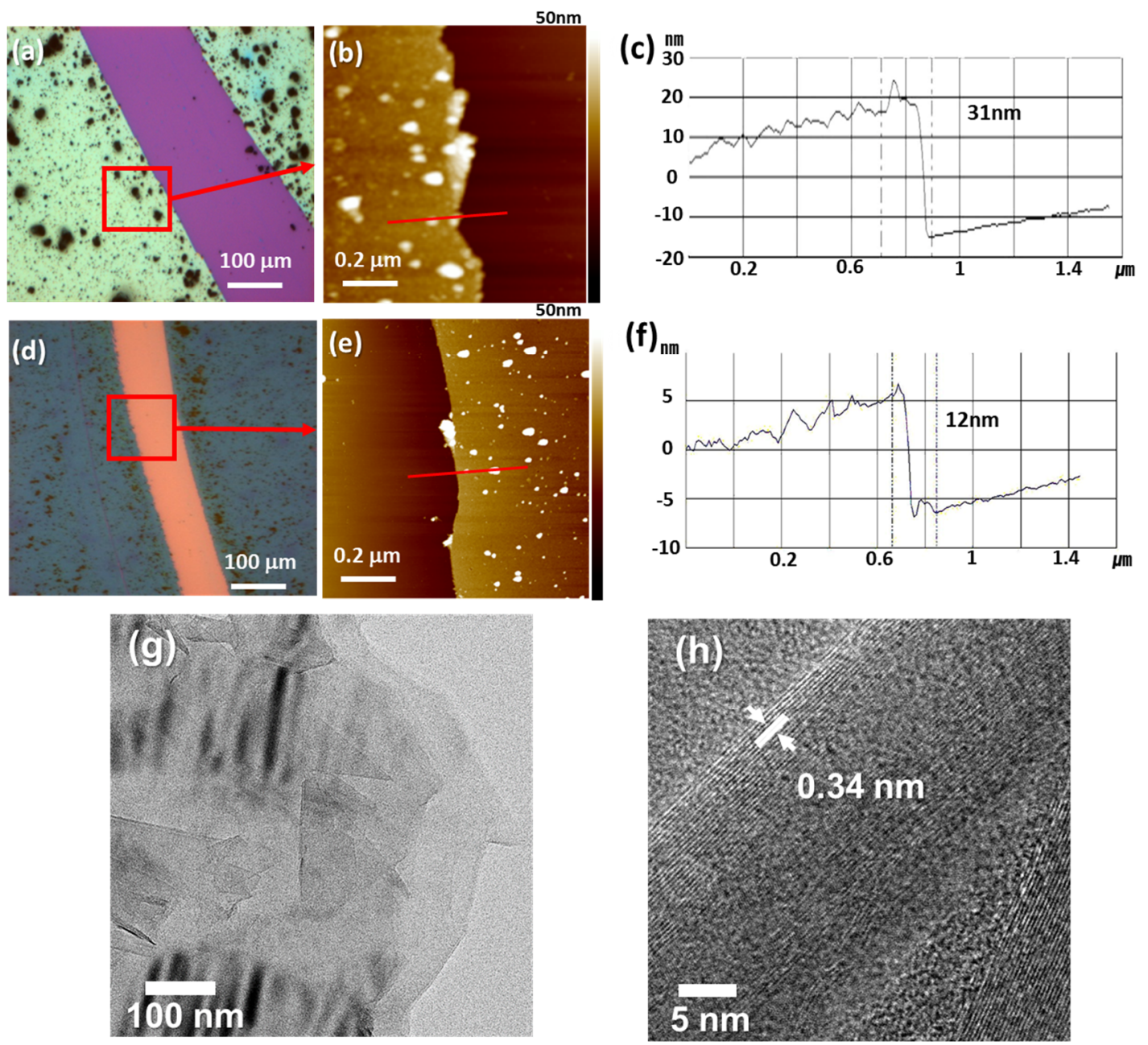

Figure 2. Optical images and tapping-mode atomic force microscopy (AFM) results of (a-c) polydopamine (PDA) and (d-f) C-PDA. (g,h) High-resolution TEM images of the C-PDA film.

\subsection{Raman and XPS}

Raman spectroscopy was performed to study the structure and electronic properties of the C-PDA nanosheet (Figure 3a). The two peaks, one at approximately $1380 \mathrm{~cm}^{-1}$ and the other at $1590 \mathrm{~cm}^{-1}$, were assigned to the $\mathrm{D}$ (disordered carbon) and $\mathrm{G}$ bands (graphitic carbon), respectively $[38,39,48]$. It is worthwhile to note that the intensity ratio of the $\mathrm{D}$ and $\mathrm{G}$ bands, $\mathrm{I}_{\mathrm{D}} / \mathrm{I}_{\mathrm{G}}$, in the PDA film was 0.69 , which is significantly low. However, after heat treatment during annealing, in comparison to the $\mathrm{D}$ peak $\left(\mathrm{I}_{\mathrm{D}} / \mathrm{I}_{\mathrm{G}}=0.97\right)$, the $\mathrm{G}$ peak indicated a generation of defects and edges. In addition, this increase in the intensity ratio also indicates doping by heteroatoms (nitrogen and oxygen) in the graphitic planes during the calcination of PDA [38]. The chemical structural analysis of PDA and C-PDA was evaluated by the X-ray photoelectron spectroscopy (XPS) spectrum (Figure 3b,c). The peaks at approximately $284.5,400.9$, and $533.5 \mathrm{eV}$ correspond to the C1s, N1s, and O1s core levels, respectively. The survey scan illustrates the existence of $6.2 \% \mathrm{~N}$ and $5.9 \% \mathrm{O}$ in C-PDA, which are lower than the typical values in PDA $(8.8 \% \mathrm{~N}$ and $14.9 \% \mathrm{O})$, thus indicating the efficiency of thermal reduction during annealing. For the C1s spectrum, the peaks at 284.7, 286.3, 287.8, 288.9, and $290.5 \mathrm{eV}$ correspond to the $\mathrm{C}-\mathrm{C}, \mathrm{C}-\mathrm{O} /$ $\mathrm{C}-\mathrm{N}, \mathrm{C}=\mathrm{O} / \mathrm{C}=\mathrm{N}, \mathrm{O}-\mathrm{C}=\mathrm{O}$, and $\pi \rightarrow \pi^{*}$ transitions, respectively. The high-resolution N1s spectra can be deconvoluted into three peaks located at 397.8, 399.6, and $402.1 \mathrm{eV}$, which can be assigned to the pyridinic N, pyrrolic N, and graphitic N, respectively. Obviously, the N1s spectrum for PDA is solely dominated by pyrrolic nitrogen. Meanwhile, the XPS survey of C-PDA exhibited a significant peak area of pyridinic nitrogen, which is comparable with that of pyrrolic nitrogen, thus indicating the 
appearance of nitrogen at the edge (or defect) of the graphitic layer. This change indicates the partial formation of a disordered structure of graphene sheets by nitrogen doping. Some reports mention that the nitrogen in the defect of the N-doped carbon is beneficial for hydrogen generation due to its high electronegativity $[57,58]$.

(a)

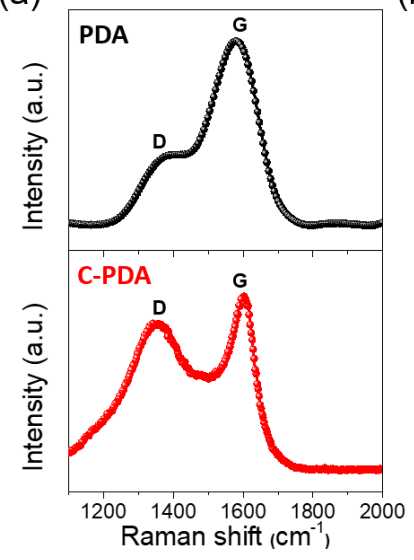

(b)

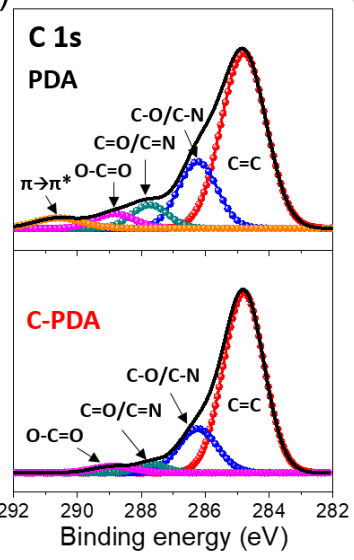

(c)

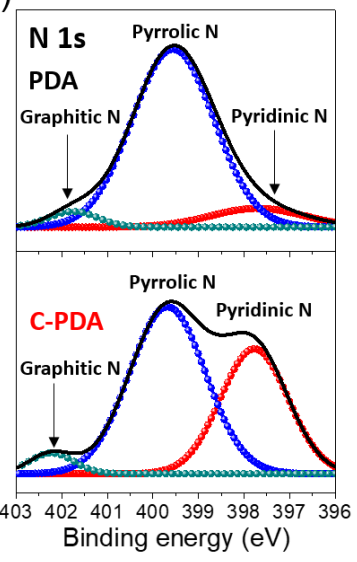

Figure 3. (a) Raman spectra and (b,c) X-ray photoelectron spectroscopy (XPS) survey of PDA and C-PDA prepared samples.

\subsection{Electrochemical Performance}

The electrochemical HER activity of the prepared samples was investigated by depositing them on a GC with a catalyst loading of $0.13 \mathrm{mg} \mathrm{cm}^{-2}$. The experiment was conducted using $1 \mathrm{M}$ perchloric acid electrolyte ( $\mathrm{pH}$ approximately 0.3 ) in a three-electrode configuration. Figure 4a shows the linear sweep voltammetry (LSV) curves of different PDA catalysts after iR compensation. For the case of onset overpotential (defined here as the overpotential $\eta$ at $1.0 \mathrm{~mA} \mathrm{~cm}^{-2}$ ), the pristine PDA exhibited a high value of $176 \mathrm{mV}$, which is close to the overpotential value of bare GC (203 mV). This value indicates that neither the GC nor the PDA is a satisfactory catalyst for the HER. In contrast, the onset overpotential of C-PDA was $68 \mathrm{mV}$, which is significantly lower than that of PDA, thus indicating that C-PDA is one of the best reported non-noble catalysts for use in acidic media to date. In addition, the $-0.13 \mathrm{~V}$ operating potential of C-PDA, which is significantly lower than that of the PDA sample $(-0.28 \mathrm{~V})$, delivers a cathodic current density of $5 \mathrm{~mA} \mathrm{~cm}^{-2}$, thus confirming the unique role of $\mathrm{N}$-doped carbon nanosheets in electrocatalytic processes. This potential value has largely outperformed those reported by previous literature for doped carbon-based materials (Table 1). It should be noted that compared to commercial Pt/C (5 wt.\%, Alfa), which is the benchmark catalyst for the HER, the activity of C-PDA still underperforms $\left(90 \mathrm{mV}\right.$ at $\left.5 \mathrm{~mA} \mathrm{~cm}^{-2}\right)$. At $10 \mathrm{~mA} \mathrm{~cm}^{-2}$, the overpotential of PDA and C-PDA are 306 and $151 \mathrm{mV}$, respectively (Figure 4b). Furthermore, C-PDA exhibits a low Tafel slope value of $45 \mathrm{mV}$ decade $^{-1}$ (Figure $4 \mathrm{c}$ ), which is also smaller than that of PDA (74 mV decade ${ }^{-1}$ ) and somewhat comparable with that of $\mathrm{Pt} / \mathrm{C}\left(42 \mathrm{mV}_{\text {decade }}{ }^{-1}\right)$, thus implying favorable HER kinetics by N-doping at the edge of the graphite layer. A small Tafel slope also suggests that the reaction proceeds through the Volmer-Heyrovsky mechanism, in which the electrochemical desorption step is rate-limiting. As discussed above, the significantly improved catalytic activity of the C-PDA film is the result of a potent combination of the following three factors: (i) the decrease in the thickness of the PDA film after calcination, which not only increases the specific surface area of material but also enables the rapid diffusion of charges/species during the reaction; (ii) the change in the chemical structure of the polymer (PDA) to a carbon network (C-PDA), which enables smaller charge-transfer resistances of the electrode; and (iii) the existence of defected nitrogen atoms that in turn contribute to the high abundance of available catalytically active sites. In addition, the long-term durability of the C-PDA electrocatalyst for HER was investigated at the potential of $-0.15 \mathrm{~V}$ and $-0.20 \mathrm{~V}$ vs. RHE 
(Figure $4 \mathrm{~d}$ ). The current density to time $(J-t)$ curves maintained more than $80 \%$ of its initial current density value of approximately $-20 \mathrm{~mA} \mathrm{~cm}^{-2}$ over $10 \mathrm{~h}$.

(a)

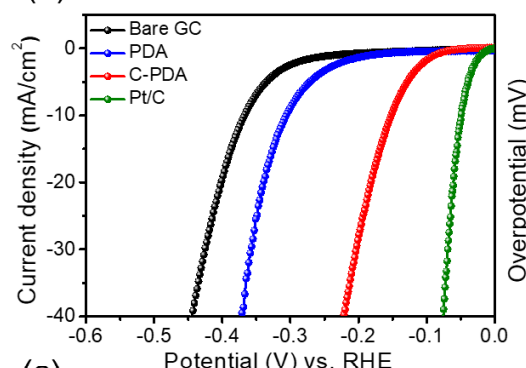

(c)

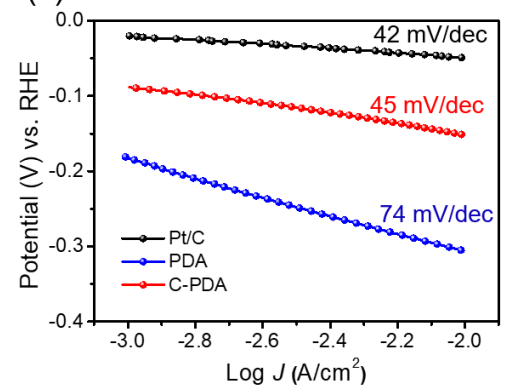

(b)

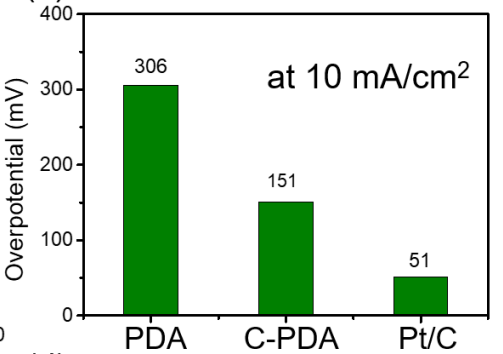

(d)

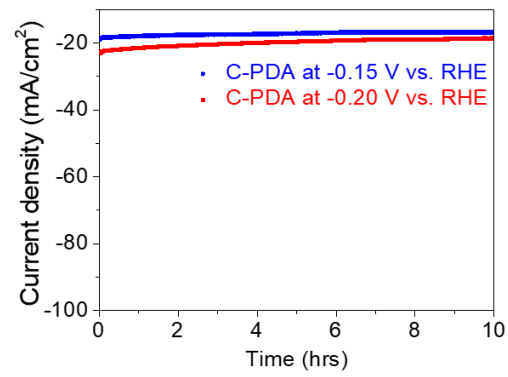

Figure 4. Electrochemical performance of prepared samples. (a) The hydrogen-evolution reaction (HER) polarization curves, (b) the overpotential value at $10 \mathrm{~mA} \mathrm{~cm}^{-2}$, (c) the corresponding Tafel slope of C-PDA samples, and (d) the chronoamperometric operation of C-PDA electrocatalyst at the potential of $-0.15 \mathrm{~V}$ and $-0.20 \mathrm{~V}$ vs. RHE during 10 hours, respectively.

Table 1. Comparison of the recent carbon-based materials for HER performance.

\begin{tabular}{|c|c|c|c|c|c|}
\hline Catalyst & Substrate & $\begin{array}{c}\eta_{\text {onset }} \\
\text { (mV vs. RHE) }\end{array}$ & $\begin{array}{l}\text { Tafel Slope } \\
\text { (mV/dec) }\end{array}$ & Electrolyte & Ref. \\
\hline N-carbon & GCE* & 343 & 187 & $1 \mathrm{M} \mathrm{KOH}$ & [41] \\
\hline $\mathrm{N}$-carbon & GCE & 307 & 170 & $1 \mathrm{M} \mathrm{KOH}$ & [58] \\
\hline N-carbon & GCE & 387 & 162 & $1 \mathrm{M} \mathrm{KOH}$ & [59] \\
\hline N-graphene & $\mathrm{RDE}^{* *}$ & 543 & 143 & $0.1 \mathrm{M} \mathrm{KOH}$ & [60] \\
\hline N-carbon & GCE & 165 & 228 & $0.5 \mathrm{M} \mathrm{H}_{2} \mathrm{SO}_{4}$ & [58] \\
\hline N-carbon & GCE & 487 & 159 & $0.5 \mathrm{M} \mathrm{H}_{2} \mathrm{SO}_{4}$ & [59] \\
\hline $\mathrm{N}$-carbon & RDE & 30 & 43 & $0.5 \mathrm{M} \mathrm{H}_{2} \mathrm{SO}_{4}$ & [61] \\
\hline $\mathrm{N}$-carbon & Graphene Foam & 300 & 147 & $0.5 \mathrm{M} \mathrm{H}_{2} \mathrm{SO}_{4}$ & [62] \\
\hline N-graphene & RDE & 378 & 116 & $0.5 \mathrm{M} \mathrm{H}_{2} \mathrm{SO}_{4}$ & [60] \\
\hline P-graphene & RDE & 452 & 133 & $0.5 \mathrm{M} \mathrm{H}_{2} \mathrm{SO}_{4}$ & [60] \\
\hline P-graphene & RDE & 601 & 159 & $0.1 \mathrm{M} \mathrm{KOH}$ & [60] \\
\hline N,S-carbon & GCE & 259 & 133 & $1 \mathrm{M} \mathrm{KOH}$ & [41] \\
\hline N,S-carbon & GCE & 201 & 77 & $0.5 \mathrm{M} \mathrm{H}_{2} \mathrm{SO}_{4}$ & [59] \\
\hline N,S-carbon & GCE & 292 & 103 & $1 \mathrm{M} \mathrm{KOH}$ & [59] \\
\hline N,S-carbon & GCE & 179 & 121 & $0.5 \mathrm{M} \mathrm{H}_{2} \mathrm{SO}_{4}$ & [63] \\
\hline N,S-carbon & GCE & 312 & 180 & $0.5 \mathrm{M} \mathrm{H}_{2} \mathrm{SO}_{4}$ & [64] \\
\hline N,P-carbon & GCE & 442 & 139 & $0.5 \mathrm{M} \mathrm{H}_{2} \mathrm{SO}_{4}$ & [59] \\
\hline N,P-carbon & GCE & 352 & 106 & $0.5 \mathrm{M} \mathrm{H}_{2} \mathrm{SO}_{4}$ & [65] \\
\hline $\mathrm{N}, \mathrm{P}$-graphene & RDE & 320 & 91 & $0.5 \mathrm{M} \mathrm{H}_{2} \mathrm{SO}_{4}$ & [60] \\
\hline $\mathrm{N}, \mathrm{P}$-graphene & RDE & 497 & 145 & $0.1 \mathrm{M} \mathrm{KOH}$ & [60] \\
\hline N,P-carbon & GCE & 418 & 118 & $1 \mathrm{M} \mathrm{KOH}$ & [59] \\
\hline N,B-carbon & GCE & 523 & 198 & $0.5 \mathrm{M} \mathrm{H}_{2} \mathrm{SO}_{4}$ & [59] \\
\hline N,B-carbon & GCE & 601 & 152 & $1 \mathrm{M} \mathrm{KOH}$ & [59] \\
\hline N-carbon & GCE & 68 & 45 & $1 \mathrm{M} \mathrm{HClO}_{4}$ & This work \\
\hline
\end{tabular}

${ }^{*}$ GCE: glassy carbon electrode, ${ }^{* *}$ RDE: rotating disk glassy carbon electrode. 


\subsection{Theoretical Calculation}

Given that N-doped carbon is a highly active catalyst for use in the HER, it is accepted that the N atoms in the carbon network are important for the water molecule-splitting process. To confirm the origin of the activity enhancement in this doped model, we performed DFT calculations to investigate the promotion effect of the primary $\mathrm{N}$-doping. Hence, the graphene framework doped by $\mathrm{N}$ atoms at different sites was constructed according to the XPS characterizations (Figure 5a). It is well-known that doping carbon with heteroatoms of different electronegativities can adjust the electron donor-acceptor behavior and thus improve the apparent catalytic activities of the doped samples [66]. Owing to the clearly distinguishable electronegativities of $\mathrm{N}$ (3.04) and C (2.55), the charge transfer between $\mathrm{N}$ and $\mathrm{C}$ is significant. Interestingly, after doping, the partial charge of nitrogen is more negative, while those of the neighboring carbons are more positive (Table 2).

(a)

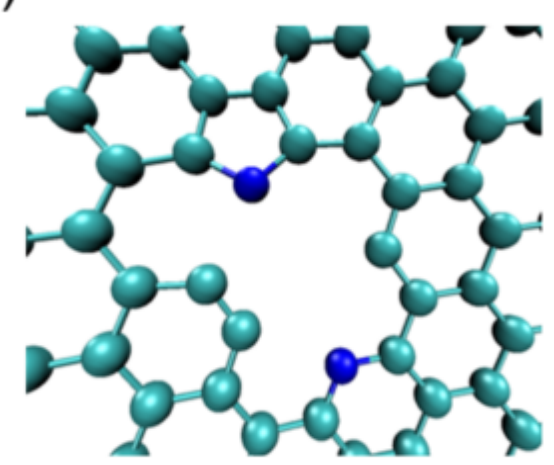

(b)

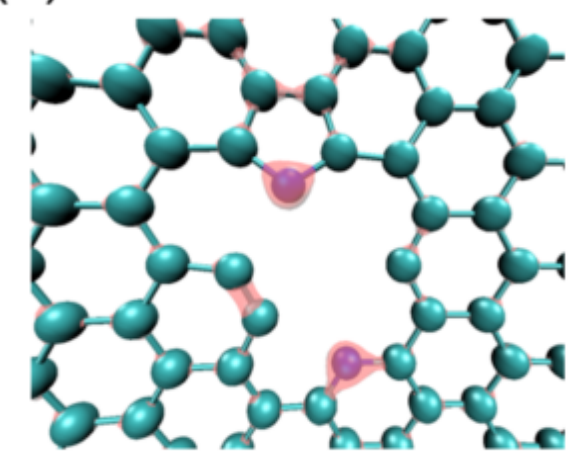

Figure 5. (a) Proposed model and (b) charge density distribution of N-doped carbon models. Isosurface value for the model is $5 \times 10^{-6} \mathrm{e} \AA^{-3}$. For the spheres in the model, cyan indicates carbon, and the blue indicates nitrogen, while hydrogen is not shown in the model. Herein, we construct a nitrogen-doped carbon model based on the XPS results.

Table 2. Calculated parameters of proposed models.

\begin{tabular}{cccc}
\hline Model & Partial Charge of N & $\begin{array}{c}\text { Partial Charge of } \\
\text { Neighbor C }\end{array}$ & $\begin{array}{c}\text { Dipole Moment } \\
\text { (Debye) }\end{array}$ \\
\hline$-\mathrm{NH}_{2}$ & -0.362 & 0.038 & 1.672 \\
$-\mathrm{N}-\mathrm{H}$ & -0.356 & $0.046 \pm 0.008$ & 1.915 \\
$-\mathrm{N}=$ & -0.325 & $0.077 \pm 0.032$ & 0.762 \\
\hline
\end{tabular}

Additionally, our calculation results demonstrate that the charge density differences around nitrogen atoms at different sites are highly divergent. Specifically, the partial charge of $-\mathrm{N}=$ exhibits a value of -0.246 while the partial charge of $-\mathrm{N}-\mathrm{H}$ exhibits a value of -0.275 . These phenomena suggest that such a significant activity enhancement is caused by not only the $\mathrm{N}$-doping but also the various sites of such $\mathrm{N}$ atoms. Thus, the catalytic enhancement can be attributed to the change in the electron charge density. Previous theoretical studies on graphene-based materials have confirmed that the adsorption strengths of $\mathrm{H}^{*}$, which are the key reaction intermediates of the HER, exhibit a correlation with the electron density difference $[67,68]$. Hence, a large number of carbon atoms could serve as electrocatalytically active sites to adsorb the $\mathrm{H}^{*}$ reaction intermediates after tertiary/aromatic $\mathrm{N}$-doping. Consequently, the apparent activity of the HER is remarkably boosted compared to that achieved with single doping.

\section{Conclusions}

In summary, due to the advantages of PDA chemistry, we have presented a novel strategy to produce N-doped nanocarbons as a potential candidate for the hydrogen-evolution reaction. 
C-PDA nanosheets exhibit outstanding electrocatalytic activity during the HER. The combination of experimental data and DFT calculations further confirms that such excellent activity of the N-doped carbon originates from the formation of a large number of electrocatalytically active sites. The required overpotential of the C-PDA at $5 \mathrm{~mA} / \mathrm{cm}^{2}$ is $130 \mathrm{mV}$, and its Tafel slope is $45 \mathrm{mV} /$ decade. Experimental characterizations confirm that the excellent performance of the nanosheets can be attributed to multisite nitrogen doping, while theoretical computations confirm the promotion effect of tertiary/aromatic nitrogen doping in enhancing the spin density of doped samples, and consequently in forming highly electroactive sites for HER application. Our approach in this study has resulted in a new design strategy to prepare non-noble catalysts exhibiting high efficiency for hydrogen production.

Author Contributions: D.N.N. conducted the experiments and theoretical calculations. J.K.K. and U.S. ideated and supervised this project. All authors contributed in the preparation of the manuscript. All authors have read and agreed to the published version of the manuscript.

Funding: This work supported by the National Research Foundation of Korea grant funded by the Ministry of Science, ICT, and Future Planning, Republic of Korea (2018R1C1B6001267, 2018R1A5A1025224, and 2019R1F1A1041822) and Creative Materials Discovery Program through the National Research Foundation of Korea (NRF-2016M3D1A1021141). This study has been conducted with the support of the Korea Institute of Industrial Technology as "Development of smart textronic products based on electronic fibers and textiles (KITECH JA-19-0001)" and the Gyeongi-Do Technology Development Program as "Development of smart textronic products based on electronic fibers and textiles (KITECH IZ-19-0003)."

Conflicts of Interest: The authors declare no conflict of interest.

\section{References}

1. Greeley, J.; Jaramillo, T.F.; Bonde, J.; Chorkendorff, I.; Nørskov, J.K. Computational high-throughput screening of electrocatalytic materials for hydrogen evolution. Nat. Mater. 2006, 5, 909-913. [CrossRef] [PubMed]

2. McKone, J.R.; Marinescu, S.C.; Brunschwig, B.S.; Winkler, J.R.; Gray, H.B. Earth-abundant hydrogen evolution electrocatalysts. Chem. Sci. 2014, 5, 865-878. [CrossRef]

3. Morales-Guio, C.G.; Stern, L.A.; Hu, X. Nanostructured hydrotreating catalysts for electrochemical hydrogen evolution. Chem. Soc. Rev. 2014, 43, 6555-6569. [CrossRef] [PubMed]

4. Nørskov, J.K.; Bligaard, T.; Logadottir, A.; Kitchin, J.R.; Chen, J.G.; Pandelov, S.; Stimming, U. Trends in the exchange current for hydrogen evolution. J. Electrochem. Soc. 2005, 152, J23. [CrossRef]

5. Zhang, K.; Kim, J.K.; Ma, M.; Yim, S.Y.; Lee, C.L.; Shin, H.; Park, J.H. Delocalized electron accumulation at nanorod tips: Origin of efficient $\mathrm{H} 2$ generation. Adv. Funct. Mater. 2016, 26, 4527-4534. [CrossRef]

6. Zheng, Y.; Jiao, Y.; Zhu, Y.; Li, L.H.; Han, Y.; Chen, Y.; Du, A.; Jaroniec, M.; Qiao, S.Z. Hydrogen evolution by a metal-free electrocatalyst. Nat. Commun. 2014, 5, 3783. [CrossRef]

7. Kornienko, N.; Resasco, J.; Becknell, N.; Jiang, C.M.; Liu, Y.S.; Nie, K.; Sun, X.; Guo, J.; Leone, S.R.; Yang, P. Operando spectroscopic analysis of an amorphous cobalt sulfide hydrogen evolution electrocatalyst. J. Am. Chem. Soc. 2015, 137, 7448-7455. [CrossRef]

8. Benck, J.D.; Hellstern, T.R.; Kibsgaard, J.; Chakthranont, P.; Jaramillo, T.F. Catalyzing the hydrogen evolution reaction (HER) with molybdenum sulfide nanomaterials. ACS Catal. 2014, 4, 3957-3971. [CrossRef]

9. Morales-Guio, C.G.; Hu, X. Amorphous molybdenum sulfides as hydrogen evolution catalysts. Acc. Chem. Res. 2014, 47, 2671-2681. [CrossRef]

10. Wan, C.; Regmi, Y.N.; Leonard, B.M. Multiple phases of molybdenum carbide as electrocatalysts for the hydrogen evolution reaction. Angew. Chem. Int. Ed. 2014, 53, 6407-6410. [CrossRef]

11. Ma, R.; Zhou, Y.; Chen, Y.; Li, P.; Liu, Q.; Wang, J. Ultrafine molybdenum carbide nanoparticles composited with carbon as a highly active hydrogen-evolution electrocatalyst. Angew. Chem. Int. Ed. 2015, 54, 14723-14727. [CrossRef] [PubMed]

12. An, T.Y.; Surendran, S.; Kim, H.; Choe, W.S.; Kim, J.K.; Sim, U. A polydopamine-mediated biomimetic facile synthesis of molybdenum carbide-phosphide nanodots encapsulated in carbon shell for electrochemical hydrogen evolution reaction with long-term durability. Compos. Part B Eng. 2019, 175, 107071. [CrossRef]

13. Popczun, E.J.; McKone, J.R.; Read, C.G.; Biacchi, A.J.; Wiltrout, A.M.; Lewis, N.S.; Schaak, R.E. Nanostructured nickel phosphide as an electrocatalyst for the hydrogen evolution reaction. J. Am. Chem. Soc. 2013, 135, 9267-9270. [CrossRef] [PubMed] 
14. Popczun, E.J.; Read, C.G.; Roske, C.W.; Lewis, N.S.; Schaak, R.E. Highly active electrocatalysis of the hydrogen evolution reaction by cobalt phosphide nanoparticles. Angew. Chem. Int. Ed. 2014, 53, 5427-5430. [CrossRef] [PubMed]

15. Xiao, P.; Chen, W.; Wang, X. A review of phosphide-based materials for electrocatalytic hydrogen evolution. Adv. Energy Mater. 2015, 5, 1500985. [CrossRef]

16. Zeng, M.; Wang, H.; Zhao, C.; Wei, J.; Qi, K.; Wang, W.; Bai, X. Nanostructured amorphous nickel boride for highefficiency electrocatalytic hydrogen evolution over a broad $\mathrm{pH}$ range. ChemCatChem 2016, 8, 708-712. [CrossRef]

17. Masa, J.; Weide, P.; Peeters, D.; Sinev, I.; Xia, W.; Sun, Z.; Somsen, C.; Muhler, M.; Schuhmann, W. Amorphous cobalt boride (CO2B) as a highly efficient nonprecious catalyst for electrochemical water splitting: Oxygen and hydrogen evolution. Adv. Energy Mater. 2016, 6, 1502313. [CrossRef]

18. Vrubel, H.; Hu, X. Molybdenum boride and carbide catalyze hydrogen evolution in both acidic and basic solutions. Angew. Chem. Int. Ed. 2012, 51, 12703-12706. [CrossRef]

19. Yang, L.; Jiang, S.; Zhao, Y.; Zhu, L.; Chen, S.; Wang, X.; Wu, Q.; Ma, J.; Ma, Y.; Hu, Z. Boron-doped carbon nanotubes as metal-free electrocatalysts for the oxygen reduction reaction. Angew. Chem. Int. Ed. 2011, 50, 7132-7135. [CrossRef]

20. Chen, S.; Bi, J.; Zhao, Y.; Yang, L.; Zhang, C.; Ma, Y.; Wu, Q.; Wang, X.; Hu, Z. Nitrogen-doped carbon nanocages as efficient metal-free electrocatalysts for oxygen reduction reaction. Adv. Mater. 2012, 24, 5593-5597. [CrossRef]

21. Shibuya, R.; Kondo, T.; Nakamura, J. Active sites in nitrogen-doped carbon materials for oxygen reduction reaction. In Carbon-Based Metal-Free Catalysts: Design and Applications; John Wiley \& Sons: Hoboken, NJ, USA, 2018; Volume 1-2, pp. 227-249. ISBN 9783527811458.

22. Mamtani, K.; Jain, D.; Dogu, D.; Gustin, V.; Gunduz, S.; Co, A.C.; Ozkan, U.S. Insights into oxygen reduction reaction (ORR) and oxygen evolution reaction (OER) active sites for nitrogen-doped carbon nanostructures (CNx) in acidic media. Appl. Catal. B Environ. 2018, 220, 88-97. [CrossRef]

23. Hu, C.; Dai, L. Multifunctional carbon-based metal-free electrocatalysts for simultaneous oxygen reduction, oxygen evolution, and hydrogen evolution. Adv. Mater. 2017, 29, 1604942. [CrossRef] [PubMed]

24. Cheng, Y.; Jiang, S.P. Advances in electrocatalysts for oxygen evolution reaction of water electrolysis-from metal oxides to carbon nanotubes. Prog. Nat. Sci. Mater. Int. 2015, 25, 545-553. [CrossRef]

25. Gomez, I.J.; Arnaiz, B.; Cacioppo, M.; Arcudi, F.; Prato, M. Nitrogen-doped carbon nanodots for bioimaging and delivery of paclitaxel. J. Mater. Chem. B 2018, 6, 1-3. [CrossRef]

26. Deng, J.; Ren, P.; Deng, D.; Bao, X. Enhanced electron penetration through an ultrathin graphene layer for highly efficient catalysis of the hydrogen evolution reaction. Angew. Chem. Int. Ed. 2015, 54, 2100-2104. [CrossRef]

27. Wang, J.; Xu, F.; Jin, H.; Chen, Y.; Wang, Y. Non-noble metal-based carbon composites in hydrogen evolution reaction: Fundamentals to applications. Adv. Mater. 2017, 29, 1605838. [CrossRef]

28. Qu, K.; Zheng, Y.; Dai, S.; Qiao, S.Z. Graphene oxide-polydopamine derived N, S-codoped carbon nanosheets as superior bifunctional electrocatalysts for oxygen reduction and evolution. Nano Energy 2016, 19, 373-381. [CrossRef]

29. Zheng, Y.; Jiao, Y.; Ge, L.; Jaroniec, M.; Qiao, S.Z. Two-step boron and nitrogen doping in graphene for enhanced synergistic catalysis. Angew. Chem. Int. Ed. 2013, 52, 3110-3116. [CrossRef]

30. Chen, S.; Duan, J.; Jaroniec, M.; Qiao, S.Z. Nitrogen and oxygen dual-doped carbon hydrogel film as a substrate-free electrode for highly efficient oxygen evolution reaction. Adv. Mater. 2014, 26, 2925-2930. [CrossRef]

31. Jiao, Y.; Zheng, Y.; Jaroniec, M.; Qiao, S.Z. Design of electrocatalysts for oxygen-and hydrogen-involving energy conversion reactions. Chem. Soc. Rev. 2015, 44, 2060-2086. [CrossRef]

32. Sim, Y.; John, J.; Moon, J.; Sim, U. Photo-assisted hydrogen evolution with reduced graphene oxide catalyst on silicon nanowire photocathode. Appl. Sci. 2018, 8, 2046. [CrossRef]

33. Sim, U.; Moon, J.; An, J.; Kang, J.H.; Jerng, S.E.; Moon, J.; Cho, S.P.; Hong, B.H.; Nam, K.T. N-doped graphene quantum sheets on silicon nanowire photocathodes for hydrogen production. Energy Environ. Sci. 2015, 8, 1329-1338. [CrossRef]

34. Sim, U.; Yang, T.Y.; Moon, J.; An, J.; Hwang, J.; Seo, J.H.; Lee, J.; Kim, K.Y.; Lee, J.; Han, S.; et al. N-doped monolayer graphene catalyst on silicon photocathode for hydrogen production. Energy Environ. Sci. 2013, 6, 3658-3664. [CrossRef]

35. Zheng, Y.; Jiao, Y.; Jaroniec, M.; Qiao, S.Z. Advancing the electrochemistry of the hydrogen-evolution reaction through combining experiment. Angew. Chem. Int. Ed. 2015, 54, 52-65. [CrossRef] [PubMed] 
36. Yan, H.; Tian, C.; Wang, L.; Wu, A.; Meng, M.; Zhao, L.; Fu, H. Phosphorus-modified tungsten nitride/reduced graphene oxide as a high-performance, non-noble-metal electrocatalyst for the hydrogen evolution reaction. Angew. Chem. Int. Ed. 2015, 54, 6325-6329. [CrossRef] [PubMed]

37. Yang, J.; Voiry, D.; Ahn, S.J.; Kang, D.; Kim, A.Y.; Chhowalla, M.; Shin, H.S. Two-dimensional hybrid nanosheets of tungsten disulfide and reduced graphene oxide as catalysts for enhanced hydrogen evolution. Angew. Chem. Int. Ed. 2013, 52, 13751-13754. [CrossRef]

38. Li, R.; Parvez, K.; Hinkel, F.; Feng, X.; Müllen, K. Bioinspired wafer-scale production of highly stretchable carbon films for transparent conductive electrodes. Angew. Chem. Int. Ed. 2013, 52, 5535-5538. [CrossRef]

39. Yu, X.; Fan, H.; Liu, Y.; Shi, Z.; Jin, Z. Characterization of carbonized polydopamine nanoparticles suggests ordered supramolecular structure of polydopamine. Langmuir 2014, 30, 5497-5505. [CrossRef]

40. Kong, J.; Yee, W.A.; Yang, L.; Wei, Y.; Phua, S.L.; Ong, H.G.; Ang, J.M.; Li, X.; Lu, X. Highly electrically conductive layered carbon derived from polydopamine and its functions in SnO2-based lithium ion battery anodes. Chem. Commun. 2012, 48, 10316-10318. [CrossRef]

41. Qu, K.; Zheng, Y.; Jiao, Y.; Zhang, X.; Dai, S.; Qiao, S.Z. Polydopamine-inspired, dual heteroatom-doped carbon nanotubes for highly efficient overall water splitting. Adv. Energy Mater. 2017, 7, 1602068. [CrossRef]

42. Xian, S.; Xu, F.; Zhao, Z.; Li, Y.; Li, Z.; Xia, Q.; Xiao, J.; Wang, H. A novel carbonized polydopamine (C-PDA) adsorbent with high CO2 adsorption capacity and water vapor resistance. AIChE J. 2016, 62, 3730-3738. [CrossRef]

43. Zhou, W.; Xiao, X.; Cai, M.; Yang, L. Polydopamine-coated, nitrogen-doped, hollow carbon-sulfur double-layered core-shell structure for improving lithium-sulfur batteries. Nano Lett. 2014, 14, 5250-5256. [CrossRef] [PubMed]

44. Liu, R.; Guo, Y.; Odusote, G.; Qu, F.; Priestley, R.D. Core-shell Fe3O4 polydopamine nanoparticles serve multipurpose as drug carrier, catalyst support and carbon adsorbent. ACS Appl. Mater. Interfaces 2013, 5, 9167-9171. [CrossRef]

45. Messersmith, P.B.; Miller, W.M.; Dellatore, S.M.; Lee, H. Mussel-inspired surface chemistry for multifunctional coatings. Science 2007, 318, 426-431.

46. Zhang, L.; Shi, J.; Jiang, Z.; Jiang, Y.; Qiao, S.; Li, J.; Wang, R.; Meng, R.; Zhu, Y.; Zheng, Y. Bioinspired preparation of polydopamine microcapsule for multienzyme system construction. Green Chem. 2011, 13, 300-306. [CrossRef]

47. Yin, X.B.; Liu, D.Y. Polydopamine-based permanent coating capillary electrochromatography for auxin determination. J. Chromatogr. A 2008, 1212, 130-136. [CrossRef]

48. Li, H.; Aulin, Y.V.; Frazer, L.; Borguet, E.; Kakodkar, R.; Feser, J.; Chen, Y.; An, K.; Dikin, D.A.; Ren, F. Structure evolution and thermoelectric properties of carbonized polydopamine thin films. ACS Appl. Mater. Interfaces 2017, 9, 6655-6660. [CrossRef]

49. Ito, Y.; Cong, W.; Fujita, T.; Tang, Z.; Chen, M. High catalytic activity of nitrogen and sulfur co-doped nanoporous graphene in the hydrogen evolution reaction. Angew. Chem. Int. Ed. 2015, 54, 2131-2136. [CrossRef]

50. Vaselbehagh, M.; Karkhanechi, H.; Mulyati, S.; Takagi, R.; Matsuyama, H. Undefined Improved antifouling of anion-exchange membrane by polydopamine coating in electrodialysis process. Desalination 2014, 332, 126-133. [CrossRef]

51. Wang, J.; Zhou, S.; Huang, J.; Zhao, G.; Liu, Y. Interfacial modification of basalt fiber filling composites with graphene oxide and polydopamine for enhanced mechanical and tribological properties. RSC Adv. 2018, 8 , 12222-12231. [CrossRef]

52. Miksa, B. Fluorescent dyes used in polymer carriers as imaging agents in anticancer therapy. Med. Chem. (Los. Angeles) 2016, 6, 2161-0444. [CrossRef]

53. Neese, F. Software update: The ORCA program system, version 4.0. Wiley Interdiscip. Rev. Comput. Mol. Sci. 2018, 8, e1327. [CrossRef]

54. Grimme, S.; Antony, J.; Ehrlich, S.; Krieg, H. A consistent and accurate ab initio parametrization of density functional dispersion correction (DFT-D) for the 94 elements H-Pu. J. Chem. Phys 2010, 132, 154104. [CrossRef]

55. Wang, Z.; Li, J.; Tang, F.; Lin, J.; Jin, Z. Polydopamine nanotubes-templated synthesis of TiO2 and its photocatalytic performance under visible light. RSC Adv. 2017, 7, 23535-23542. [CrossRef]

56. Huang, J.Y. HRTEM and EELS studies of defects structure and amorphous-like graphite induced by ball-milling. Acta Mater. 1999, 47, 1801-1808. [CrossRef] 
57. Li, D.J.; Maiti, U.N.; Lim, J.; Choi, D.S.; Lee, W.J.; Oh, Y.; Lee, G.Y.; Kim, S.O. Molybdenum sulfide/N-doped CNT forest hybrid catalysts for high-performance hydrogen evolution reaction. Nano Lett. 2014, 14, 1228-1233. [CrossRef] [PubMed]

58. Yang, F.; Chen, Y.; Cheng, G.; Chen, S.; Luo, W. Ultrathin nitrogen-doped carbon coated with CoP for efficient hydrogen evolution. ACS Catal. 2017, 7, 3824-3831. [CrossRef]

59. Qu, K.; Zheng, Y.; Zhang, X.; Davey, K.; Dai, S.; Qiao, S.Z. Promotion of electrocatalytic hydrogen evolution reaction on nitrogen-doped carbon nanosheets with secondary heteroatoms. ACS Nano 2017, 11, 7293-7300. [CrossRef]

60. Zheng, Y.; Jiao, Y.; Li, L.H.; Xing, T.; Chen, Y.; Jaroniec, M.; Qiao, S.Z. Toward design of synergistically active carbon-based catalysts for electrocatalytic hydrogen evolution. ACS Nano 2014, 8, 5290-5296. [CrossRef]

61. Jiang, H.; Gu, J.; Zheng, X.; Liu, M.; Qiu, X.; Wang, L.; Li, W.; Chen, Z.; Ji, X.; Li, J. Defect-rich and ultrathin N doped carbon nanosheets as advanced trifunctional metal-free electrocatalysts for the ORR, OER and HER. Energy Environ. Sci. 2019, 12, 322-333. [CrossRef]

62. Zhang, J.; Liu, P.; Wang, G.; Zhang, P.P.; Zhuang, X.D.; Chen, M.W.; Weidinger, I.M.; Feng, X.L. Ruthenium/nitrogen-doped carbon as an electrocatalyst for efficient hydrogen evolution in alkaline solution. J. Mater. Chem. A 2017, 5, 25314-25318. [CrossRef]

63. Mulyadi, A.; Zhang, Z.; Dutzer, M.; Liu, W.; Deng, Y. Facile approach for synthesis of doped carbon electrocatalyst from cellulose nanofibrils toward high-performance metal-free oxygen reduction and hydrogen evolution. Nano Energy 2017, 32, 336-346. [CrossRef]

64. Naresh Kumar, T.; Chandrasekaran, N.; Lakshminarasimha Phani, K. Structural and electronic modification of MoS2 nanosheets using S-doped carbon for efficient electrocatalysis of the hydrogen evolution reaction. Chem. Commun. 2015, 51, 5052-5055. [CrossRef] [PubMed]

65. Lin, Y.; Pan, Y.; Zhang, J. CoP nanorods decorated biomass derived N, P co-doped carbon flakes as an efficient hybrid catalyst for electrochemical hydrogen evolution. Electrochim. Acta 2017, 232, 561-569. [CrossRef]

66. Yan, Y.; Thia, L.; Xia, B.Y.; Ge, X.; Liu, Z.; Fisher, A.; Wang, X. Construction of efficient 3D gas evolution electrocatalyst for hydrogen evolution: Porous FeP nanowire arrays on graphene sheets. Adv. Sci. 2015, 2, 1500120. [CrossRef]

67. Zhang, L.; Xia, Z. Mechanisms of oxygen reduction reaction on nitrogen-doped graphene for fuel cells. J. Phys. Chem. C 2011, 115, 11170-11176. [CrossRef]

68. Sidik, R.A.; Anderson, A.B.; Subramanian, N.P.; Kumaraguru, S.P.; Popov, B.N. O2 reduction on graphite and nitrogen-doped graphite: Experiment and theory. J. Phys. Chem. B 2006, 110, 1787-1793. [CrossRef]

(C) 2020 by the authors. Licensee MDPI, Basel, Switzerland. This article is an open access article distributed under the terms and conditions of the Creative Commons Attribution (CC BY) license (http://creativecommons.org/licenses/by/4.0/). 